\title{
CÁC ĐẶC TRƯNG CƠ BẢN CỦA VIỆC NGHIÊN CƯU CHUYỂN DỊCH CÁC MẢNG KIẾN TẠO CỦA VỎ TRÁI ĐẤT
}

\author{
HÀ MINH HÒA \\ Viện Khoa học Đo đạc và Bản đồ
}

\section{Tóm tắt:}

Bài báo khoa học này phân tích các cơ sở khoa học và thực tiễn của việc nghiên cứu chuyển dịch của các mảng kiến tạo. Các kết quả nghiên cứu trong bài báo này sẽ cho phép phân biệt sự khác nhau giữa nghiên cứu chuyển dịch mảng kiến tạo và nghiên cứu hoạt động của các đới đưt gãy nhằm định hướng cho nghiên cứu địa động lực ở Việt Nam.

\section{1. Đặt vấn đề}

Kiến tạo học mảng (Plate Tectonics) là chuyên ngành của Địa chất được phát triển dựa trên lý thuyết Lục địa trôi (Continental Drift) của nhà địa chất và khi tượng học người Đức Alfred Wegener (1880 - 1930) được đưa ra lần đầu tiên vào năm 1912. Kiến tạo học coi lớp ngoài của Trái đất được chia thành vô số mảng trượt đi trên lớp manti và là lớp cứng hơn so với manti tạo nên tầng thạch quyển (Lithosphere) của Trái đất. Các mảng thạch quyển kiến tạo bao gồm lớp vỏ đại dương và lớp vỏ lục địa. Bề dầy của lớp vỏ đại dương vào khoảng $6 \mathrm{~km}$ ở các khu vực đồi gò giữa đại dương và khoảng $100 \mathrm{~km}$ tại các đới hút chìm. Lớp vỏ ngoài của Trái đất bao gồm tầng thạch quyển và quyển mềm (Asthenosphere), trong đó tầng thạch quyển lạnh, cứng, có mật độ cao hơn còn quyển mềm đặc sền sệt, nóng, có mật độ thấp hơn và di chuyển dễ dàng hơn. Do tính dẫn nhiệt, tầng thạch quyển làm mất nhiệt của lớp trên của quyển mềm, còn quyển mềm truyền nhiệt do tính chất đối lưu. Kết quả là lớp trên của quyển mềm mất nhiệt, trở nên nặng hơn và lại di chuyển xuống dưới, còn lớp dưới của quyển mềm lại di chuyển lên trên. Sự đối lưu nhiệt của lớp quyển mềm làm mảng kiến tạo thuộc tầng thạch quyển di chuyển. Ngoài ra, việc chuyển dịch của các mảng kiến tạo còn được gây ra bởi hiện tượng triều dưới lực hút của Mặt trăng, Mặt trời, do sự biến dạng toàn cầu mặt geoid dưới sự xê dịch nhỏ của trục quay của Trái đất so với lớp vỏ Trái đất và do các hiệu ứng biến dạng nhỏ của lớp vỏ Trái đất dưới sự rung lắc và chuyển động quay của sự quay của Trái đất trong khoảng thời gian nhỏ. Các nghiên cứu địa chất đã phát hiện được sự biến thiên của từ trường dưới đáy đại dương. Các dãy núi giữa đại dương tạo nên các vùng cấu trúc yếu mà ở đó đáy đại dương bị tách thành hai theo chiều dọc theo đỉnh của dãy núi. Macma từ độ sâu bên trong Trái đất phun trào ra tại các vùng cấu trúc yếu dọc theo các đỉnh của các dãy núi để tạo ra lớp vỏ đại dương mới. Quá trình này dược gọi là sự mở rộng đáy đại dương (oceanic spreading) và kéo dài hàng triệu năm liên tục để tạo ra đáy đại dương mới (Plate tectonics).

Tại những nơi mà các mảng kiến tạo gặp nhau, chuyển động tương đối của chúng tạo nên các dạng biên: hội tụ, phân kỳ và chuyển tiếp. Biên chuyển tiếp giữa hai mảng thạch quyển xẩy ra khu hai mảng trượt qua nhau dọc theo các đứt gãy chuyển tiếp mà ở đó các mảng không được tạo ra hoặc bị phá hủy.

Các đứt gãy chuyển tiếp xuất hiện dọc theo trung tâm mở rộng. Biên phân kỳ xuất hiện

Ngày nhận bài: 20/02/2017, ngày chuyển phản biện: 21/02/2017, ngày chấp nhận phản biện: 05/03/2017, ngày chấp nhận đăng: 06/3/2017 
khi hai mảng chuyển dịch xa dần nhau. Tại các vùng khe nứt đại dương với đại dương, các biên phân kỳ hình thành bởi sự mở rộng đáy đại dương và tiếp theo hình thành các vịnh biển mới. Tại các vùng khe nứt lục địa với lục địa, các biên phân kỳ có thể tạo ra vịnh biển mới để tạo nên sự phân chia lục địa, sự mở rộng v.v... Biên hội tụ xuất hiện khi hai mảng kiến tạo chuyển dịch về phía nhau và tạo ra các đới hút chìm (một mảng nằm dưới mảng kia) (subduction zone) hoặc sự va chạm lục địa. Tại các khu vực hút chìm đại dương vào lục địa, thạch quyển đại dương đặc hơn chìm sâu xuống dưới thạch quyển lục địa kém đặc hơn. Tại các khu vực hút chìm đại dương vào đại dương, lớp vỏ đặc hơn, lạnh hơn sẽ trượt xuống dưới lớp vỏ kém đặc hơn. Tại các biên của các mảng kiến tạo thường xẩy ra động đất, hoạt động núi lửa, quá trình tạo núi và sự xâm lấn của đại dương. Dọc theo các biên hội tụ, sự sụt lún (subduction) sẽ đẩy các mảng vào lớp manti. Sự mất vật chất được cân bằng bởi sự tạo thành lớp vỏ đại dương mới dọc theo các biên phân kỳ nhờ sự mở rộng đáy đại dương (seafloor spreading). Sự chuyển động của các mảng kiến tạo được gây ra bởi tổ hợp các chuyển động của đáy đại dương ngược với các dãy đồi gò mở rộng (do các sự biến thiên về địa hình và mật độ vật chất của lớp vỏ gây ra sự thay đổi của các lực trọng trường) và sự lôi kéo (drag) với sự hút xuống tại các đới chìm (sụt lún) (Condie K.C. (1997); Plate tectonics).

Một số các mảng kiến tạo lớn được tập trung nghiên cứu bao gồm các mảng Thái Bình Dương, Á - Âu, Bắc Mỹ, Nam Mỹ, Nam Cực, Ân Độ, Australia, Biển Philipine, Châu Phi, A Rập, Caribe, Cocos, Juan de Fuca, Nazca, Rivera, Scotia. Các hướng chuyển dịch của các mảng kiến tạo lớn được trình bày trên hình 1 (được lấy từ tài liệu Zarov V.E. (2002)).

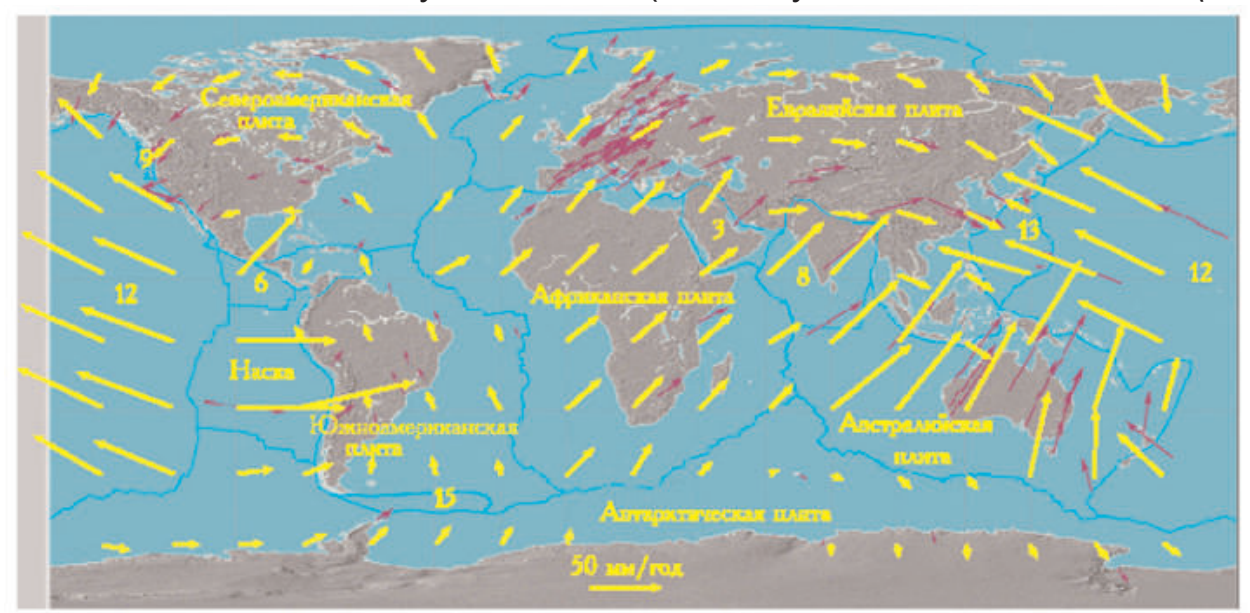

Hình 1: Các hướng chuyển dịch của các mảng kiến tạo lớn

Hiện nay đang tồn tại các cách tiếp cận khác nhau như động học, vật lý nhiệt, địa hóa trong nghiên cứu chuyển động mảng. Trong bài báo khoa học này chúng ta sẽ sử dụng cách tiếp cận động học trên cơ sở sử dụng chung các dũ liệu trắc địa, địa chất và địa vật lý để nghiên cứu chuyển dịch của các mảng kiến tạo. Ngày nay việc nghiên cứu chuyển dịch các mảng kiến tạo được thực hiện nhờ các phương pháp VLBI, SLR, DORIS và công nghệ GNSS trên cơ sở ITRF kết hợp với mô hình động học mảng kiến tạo NNR - NUVEL - 1 A của các lĩnh vực Địa chất và Địa vật lý. Đây là một trong những lĩnh vực phối hợp hợp tác hiệu quả giữa cả ba lĩnh vực Trắc địa, Địa chất và Địa vật lý.

Do lãnh thổ Việt Nam nằm trọn trên mảng kiến tạo Á - Âu, từ năm 2012, Viện Khoa 
học Đo đạc và Bản đồ đã chủ trì và phối hợp với Viện Khoa học Địa chất và Khoáng sản đã bắt đầu triển khai các dự án của Bộ Tài nguyên và Môi trường như 'Xây dựng mạng lưới trắc địa địa động lực trên khu vực các đứt gãy thuộc miền Bắc Việt Nam phục vụ công tác dự báo tai biến tự nhiên" phủ trùm 11 đứt gãy thuộc khu vực miền Bắc, "Xây dựng mạng lưới trắc địa địa động lực trên khu vực các đứt gãy thuộc miền Trung, Tây Nguyên và Nam Bộ Việt Nam phục vụ công tác dự báo tai biến tự nhiên" phủ trùm 13 đứt gãy thuộc khu vực thuộc miền Trung, Tây Nguyên và Nam Bộ, trong giai đoạn 2013 - 2015 đã phối hợp với Liên đoàn Bản đồ địa chất miền Nam trực thuộc Tống cục Địa chất và Khoáng sán đã chủ trì triển khai dự án của Bộ Tài nguyên và Môi trường "Điều tra, đánh giá địa động lực hiện đại để hoàn thiện kịch bản biến đổi khí hậu và đề xuất giải pháp thích ứng ở vùng đồng bằng sông Cửu Long" để nghiên cứu hoạt động của 12 đứt gãy thuộc vùng đồng bằng sông Cửu Long. Các mục đích chính của các dự án nêu trên là nghiên cứu hoạt động của các đới đứt gãy phục vụ việc dự báo các tai biến tự nhiên như động đất, lũ quét, trượt lở đất v.v...

Tuy nhiên trong các giới Trắc địa và Địa chất hiện nay vẫn nẩy sinh câu hỏi: Việc nghiên cứu hoạt động của các đới đứt gãy khác việc nghiên cứu chuyển dịch mảng kiến tạo như thế nào?. Trong bài báo khoa học này sẽ nghiên cứu các đặc trưng cơ bản của việc nghiên cứu chuyển dịch mảng kiến tạo. Sự khác biệt giữa nghiên cứu hoạt động của các đới đứt gãy và nghiên cứu chuyển dịch mảng kiến tạo sẽ được phân tích trong bài báo tiếp theo.

\section{Giải quyết vấn đề}

Việc phát triển mạnh mẽ các phương pháp trắc địa vũ trụ như phương pháp Giao thoa đường đáy rất dài (VLBI) từ cuối những năm 1960, công nghệ GNSS từ giữa những năm 1980, phương pháp Đo khoảng cách laser đến vệ tinh (SLR) từ đầu những năm 1990 cùng với sự ra đời của Khung quy chiếu Trái đất quốc tế ITRF từ cuối những năm 1980 đã thúc đẩy mạnh mẽ việc nghiên cứu chuyển dịch các mảng kiến tạo của vỏ Trái đất trên cơ sở phối hợp với các lĩnh vực Địa chất và Địa vật lý.

Các mục đích chính của việc nghiên cứu chuyển dịch các mảng kiến tạo bao gồm nghiên cứu lịch sử hình thành và dự báo xu hướng hình thành các lục địa, sự phát triển các đáy đại dương gắn với sự biến đổi khí hậu toàn cầu; dự báo các trận động đất lớn, hoạt động của các núi lửa tại các biên của các mảng kiến tạo; nghiên cứu lịch sử và xu thế tạo núi v.v...

Đối với lĩnh vực Trắc địa, do các điểm thuộc các mạng lưới trắc địa vũ trụ được bố trí trên các mảng kiến tạo, nên việc nghiên cứu chuyển dịch các mảng kiến tạo cho phép hiệu chỉnh thường xuyên vị trí của các trạm quan trắc vũ trụ trong ITRF xác định. Giả thiết ITRF được xác định vào thời điểm chuẩn $\mathrm{t}_{0}$. Khi đó vào thời điểm $\mathrm{t}>\mathrm{t}_{0}$, khi xác định được các tọa độ không gian $\left(X_{t}, Y_{t}, Z_{t}\right)^{T}$ của điểm trắc địa trong ITRF, khi tính đến sự dịch chuyển của điểm trắc địa, việc chuyển các tọa độ không gian $\left(X_{t}, Y_{t}, Z_{t}\right)^{T}$ về thời điểm chuẩn $\mathrm{t}_{0}$ được thực hiện theo công thức (Petit G., Luzum B. (2010)):

$$
\left(\begin{array}{l}
X_{t_{0}} \\
Y_{t_{0}} \\
Z_{t_{0}}
\end{array}\right)=\left(\begin{array}{l}
X_{t} \\
Y_{t} \\
Z_{t}
\end{array}\right)+\left(\begin{array}{l}
\dot{X}_{t_{0}} \\
\dot{Y}_{t_{0}} \\
\dot{Z}_{t_{0}}
\end{array}\right) \cdot\left(t-t_{0}\right),
$$


ở đây tốc độ chuyển dịch của điểm trắc địa trong khoảng thời gian $\left(t-t_{0}\right)$ được xác định theo công thức:

$$
\left(\begin{array}{l}
\dot{X}_{t_{0}} \\
\dot{Y}_{t_{0}} \\
\dot{Z}_{t_{0}}
\end{array}\right)=\left(\begin{array}{l}
\dot{T}_{X} \\
\dot{T}_{Y} \\
\dot{T}_{Z}
\end{array}\right)+\dot{D} \cdot\left(\begin{array}{l}
X_{t} \\
Y_{t} \\
Z_{t}
\end{array}\right)+\dot{R} \cdot\left(\begin{array}{l}
X_{t} \\
Y_{t} \\
Z_{t}
\end{array}\right),
$$

$\left(\dot{T}_{X}, \dot{T}_{Y}, \dot{T}_{Z}\right)^{T}$ - tốc độ thay đổi các tọa độ của điểm gốc tọa độ ITRF so với tâm vật chất Trái đất, $\dot{m}$ - tốc độ thay đổi của hệ số tỷ lệ xích, góc xoay của các trục tọa độ của ITRF

$$
\dot{R}=\left(\begin{array}{ccc}
0 & -\dot{R}_{3} & \dot{R}_{2} \\
\dot{R}_{3} & 0 & -\dot{R}_{1} \\
-\dot{R}_{2} & \dot{R}_{1} & 0
\end{array}\right) .
$$

Trong tài liệu (Boucher, C. and Altamimi, Z.) đã cho các tham số $\dot{T}_{X}, \dot{T}_{Y}, \dot{T}_{Z}, \dot{D}, \dot{R}_{1}, \dot{R}_{2}, \dot{R}_{3}$ để chuyển các tọa độ không gian về ITRF2000 với $t_{0}=1997,0$ và về ITRF2005 với $t_{0}=$ 2000,0 .

Tuy nhiên, các tốc độ thay đổi $\dot{T}_{X}, \dot{T}_{Y}, \dot{T}_{Z}, \dot{D}, \dot{R}_{1}, \dot{R}_{2}, \dot{R}_{3}$ thực chất lại được gây ra bởi sự chuyển dịch của mảng kiến tạo mà trên đó được bố trí điểm trắc địa. Khi đó công thức (2) được biểu diễn dưới dạng:

$$
\left(\begin{array}{l}
\dot{X}_{t_{0}} \\
\dot{Y}_{t_{0}} \\
\dot{Z}_{t_{0}}
\end{array}\right)=\left(\begin{array}{ccc}
0 & -Z_{t} & Y_{t} \\
Z_{t} & 0 & -X_{t} \\
-Y_{t} & X_{t} & 0
\end{array}\right)\left(\begin{array}{l}
\Omega_{X} \\
\Omega_{Y} \\
\Omega_{Z}
\end{array}\right),
$$

ở đây $\Omega_{X}, \Omega_{Y}, \Omega_{Z}$ là các vận tốc quay Euler đặc trưng cho sự chuyển động của mảng kiến tạo mà trên đó được bố trí điểm trắc địa.

Vậy các vận tốc quay Euler $\Omega_{X}, \Omega_{Y}, \Omega_{Z}$ thực chất các đại lượng gì?. Động học kiến tạo mảng (plate kinematics) là chuyên ngành của các lĩnh vực Địa chất và Địa vật lý. Mô hình động học mảng kiến tạo do Leonhard Euler đề xuất vào cuối thế kỷ XVIII, theo đó chuyển động của mảng kiến tạo trên một mặt cầu được mô tả như là sự quay của vật thể xung quanh một trục cố định đi qua tâm của Quả cầu (Riquzzi F. (2008)). Trong thực tế chúng ta coi Trái đất là Quả cầu.

Trong Động học mảng kiến tạo, mỗi mảng kiến tạo $\mathrm{p}$ đều quay xung quanh một trục Euler với cực quay được gọi là cực Euler $\mathrm{P}$ nằm trển bề mặt Trái đất, thêm vào đó trục Euler đi qua tâm vật chất của Trái đất (xem trên hình 2 ). Vectơ vận tốc quay $\vec{\omega}_{p}$ nằm trên trục quay và có dấu dương nếu nó ngược với hướng kim đồng hồ (khi nhìn từ đỉnh cực). Các vận tốc quay Euler $\Omega_{X}, \Omega_{Y}, \Omega_{Z}$ là các thành phần của vectơ vận tốc quay $\overline{\omega_{p}}$. Trục 
quay cắt mặt cầu tại hai điểm Euler: một cực quay là dương trùng với tốc độ quay dương và cực kia là đối cực (antipole) âm với tốc độ quay âm (Riquzzi F. (2008)). Vectơ vận tốc quay $\vec{\omega}_{p}$ được gọi là vectơ Euler.

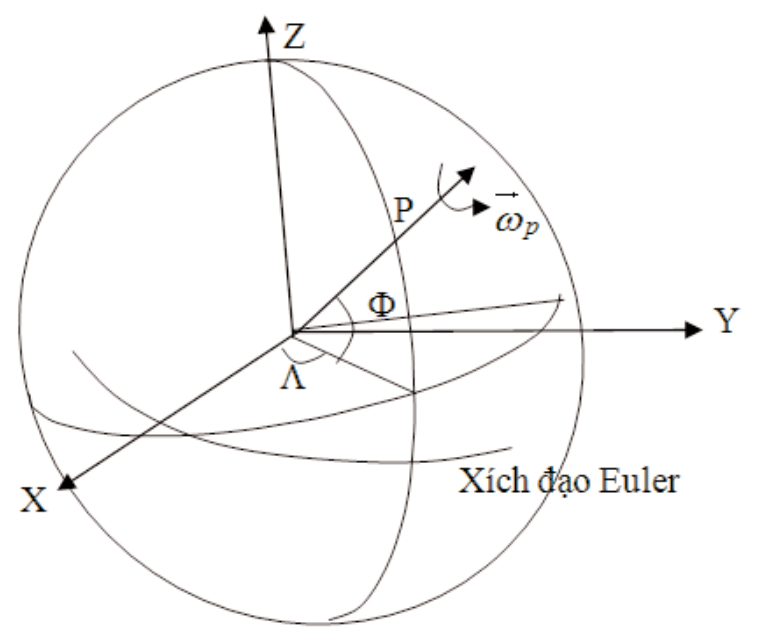

Hình 2: Cực Euler và vectơ Euler

Vĩ độ trắc địa $\Phi$ và kinh độ trắc địa $\Lambda$ của cực Euler $p$ được xác định theo các vận tốc góc Euler $\Omega_{X}, \Omega_{Y}, \Omega_{Z}$ theo công thức sau:

$$
\Phi=\operatorname{arctg}\left(\frac{\Omega_{Z}}{\sqrt{\Omega_{X}^{2}+\Omega_{Y}^{2}}}\right), \Lambda=\operatorname{arctg} \frac{\Omega_{Y}}{\Omega_{Z}} .
$$

Giả thiết chúng ta đã biết các vận tốc quay Euler $\Omega_{X}, \Omega_{Y}, \Omega_{Z}$ của mảng kiến tạo $p$. Nếu điểm trắc địa có các tọa độ trắc địa $\varphi, \lambda$ và các tọa độ không gian $\left(X_{t}, Y_{t}, Z_{t}\right)^{T}$ nằm trên mảng kiến tạo $p$, thì các vận tốc chuyển dịch các tọa độ không gian của nó được xác định theo công thức (3), phương vị $\boldsymbol{\alpha}$ của vectơ chuyển dịch ngang $V$ được xác định theo công thức $\alpha=90^{\circ}+C$ còn góc $C$ được xác định theo công thức $\sin C=\frac{\sin (\Lambda-\lambda)}{\sin a} \cdot \cos \Phi$, chiều dài cung a từ trục Euler đến điểm trắc địa được xác định theo công thức

$$
\cos a=\sin \varphi \cdot \sin \Phi+\cos \varphi \cdot \cos \Phi \cdot(\Lambda-\lambda) .
$$

Như vậy mục đích của nghiên cứu chuyển dịch mảng kiến tạo là xác định các bộ vận tốc quay Euler $\Omega_{X}, \Omega_{Y}, \Omega_{Z}$ cho các mảng kiến tạo. Đối với mỗi mảng kiến tạo, các vận tốc quay Euler $\Omega_{X}, \Omega_{Y}, \Omega_{Z}$ của mảng kiến tạo đó không chỉ cho phép hiệu chỉnh các tọa độ không gian của điểm trắc địa trong ITRF theo các công thức (1), (3), xác định tốc độ chuyển dịch và phương vị chuyển dịch của điểm đó, mà còn cho phép nghiên cứu lịch sử chuyển dịch của mảng kiến tạo trong quá trình hình thành các lục địa trong quá khứ và dự báo hoạt động của nó trong quá trình hình thành các lục địa mới trong tương lai. Từ phương hướng và tốc độ chuyển dịch của mảng kiến tạo, dựa trên đặc điểm địa chất tại các biên của mảng kiến tạo khác nhau có thể dự báo động đất và các tai biến địa chất khác v.v... 
Vậy làm thế nào để xác định được các bộ vận tốc quay Euler $\Omega_{X}, \Omega_{Y}, \Omega_{Z}$ cho các mảng kiến tạo dựa trên các dữ liệu trắc địa, địa chất và địa vật lý? Vấn đề tồn tại là các trục tọa độ của ITRF được xây dựng dựa trên Hệ thống Trái đất quy ước 1984.0 do tổ chức IERS quy định, trong khi đó các vận tốc góc Euler của các mảng kiến tạo lại tương ứng với các trục quán tính của Trái đất. Do đó vấn đề đồng chỉnh các trục tọa độ của ITRF tương ứng với các trục quán tính của Trái đất là yêu cầu khách quan với mục đích sử dụng các dữ liệu trắc địa vũ trụ đo lặp nhận được để xác định các vận tốc góc Euler của các mảng kiến tạo và nghiên cứu chuyển động cực của Trái đất. Theo lý thuyết quay của Trái đất (Theory of Earth's rotation), khi tồn tại sự bảo toàn của động lượng góc giữa hệ quy chiếu quán tính và hệ quy chiếu Trái đất khi không có lực ngoài tác động vào cả hai hệ nêu trên, động lượng góc trong hệ quy chiếu Trái đất được xác định theo công thức (Moritz, $\mathrm{H}$. and I.I. Mueller (1987)):

$$
\overrightarrow{H_{T}}=\iiint_{E} \overrightarrow{r_{T}} \otimes\left(\overrightarrow{\omega_{T}} \otimes \overrightarrow{r_{T}}\right) d M+\iiint_{E} \overrightarrow{r_{T}} \otimes \frac{d r_{T}}{d t} d M,
$$

ở đây $\overrightarrow{F_{Z}}$ - bán kính - vectơ của chất điểm có khối lượng dM, $\overrightarrow{\omega_{E}}$ - vectơ tốc độ quay của Trái đất.

Thành phần thứ hai ở vế phải của công thức trên được gọi là động lượng góc tương đối (relative angular momentum) và được ký hiệu:

$$
h=\iiint_{E} \vec{r}_{T} \otimes \frac{d \overrightarrow{r_{T}}}{d t} d M .
$$

Sự chuyển dịch của các mảng kiến tạo trên bề mặt Trái đất là một trong những tác nhân chính gây ra động lượng góc tương đối $\mathrm{h}$ (4) làm thay đổi động lượng góc và mô men xoắn trong sự quay của Trái đất so với hệ quy chiếu quán tính. Do ITRF quay cùng Trái đất, nên vấn đề được đặt ra là xây dựng ITRF sao cho nó không bị ảnh hưởng của chuyển dịch của các mảng kiến tạo trên bề mặt Trái đất. Điều này đạt được khi động lượng góc tương đối h (4) bằng 0 (Munk, W.H.\& MacDonald, G.J.F. (1960); Moritz, H. and I.I. Mueller (1987))). Khi đó ITRF tương ứng với hệ Tisserand (Tisserand system) do nhà thiên văn người Pháp Francois Félix Tisserand (1845 - 1896) đề xuất vào năm 1891, theo đó các trục được chọn sao cho ma trận quán tính I là ma trận đường chéo và động lượng góc tương đối toàn bộ của sự quay của Trái đất $\mathrm{h}=0$ với điều kiện khối lượng vật chất không đổi trên toàn cầu.

Khi đó điều kiện (4) được viết lại dưới dạng:

$$
\iiint_{E} \vec{r}_{T} \otimes \frac{d r_{T}}{d t} d M=0 .
$$

Điều kiện (5) được gọi là điều kiện mạng lưới không quay (No - Net - Rotation - NNR) và được sử dụng rộng rãi để xác định các bộ vận tốc quay Euler $\Omega_{X}, \Omega_{Y}, \Omega_{Z}$ cho các mảng kiến tạo dựa trên các dữ liệu trắc địa, địa chất và địa vật lý.

Do các mảng kiến tạo chuyển động trên bề mặt lớp manti được nhận làm mặt quy chiếu, nên việc xác định các bộ vận tốc quay Euler $\Omega_{X}, \Omega_{Y}, \Omega_{Z}$ cho các mảng kiến tạo được thực hiện nhờ các vectơ chuyển dịch ngang được suy ra từ các vectơ chuyển dịch không 
gian (3) dựa trên các dữ liệu trắc địa đo lặp. Do các chuyển dịch đứng của các mảng kiến tạo được coi bằng 0 , nên đối với mỗi điểm trắc địa có điều kiện ràng buộc (জ̦tefka $V$. (2010)):

$$
\begin{aligned}
& (Y \cdot \sin B-Z \cdot \cos B \cdot \sin L) \Omega_{X}+(Z \cdot \cos B \cdot \cos L-X \cdot \sin B) \cdot \Omega_{Y}+ \\
& +(X \cdot \cos B \cdot \sin L-Y \cdot \cos B \cdot \cos L) \cdot \Omega_{Z}=0 .
\end{aligned}
$$

Ngoài ra trên các biên của các mảng kiến tạo còn có thêm các điều kiện ràng buộc được xác định theo các dữ liệu địa chất và địa vật lý.

Dựa trên điều kiện (5) đã xây dựng được mô hình động học mảng kiến tạo (kinematic plate model) NRR - NUVEL - 1A (NUVEL - Northwestern University VELocity model) cho 16 mảng kiến tạo chính (DeMets, C., R.G. Gordon, D.F. Argus, and S. Stein (1994); McCarthy, D. D., 1996), mô hình chuyển động mảng NRR - MORVEL56 (MORVEL - MidOcean Ridge VELocity) bao trùm 56 mảng kiến tạo trong khung quy chiếu NNR với mảng quy chiếu là mảng Thái Bình Dương (DeMets, C., R. G., Gordon, and D. F., Argus (2010); Argus, D. F., Gordon, R. G., and DeMets, C., 2011). Dựa trên mô hình NNR - NUVEL - 1A đã xây dựng được mô hình chuyển dịch mảng kiến tạo ITRF2008 được trình bày ở bảng 1 (Altamimi, Z., Métivier, L., and Collilieux, X., 2012). Khi xây dựng các mô hình nêu trên, các tốc độ chuyển dịch ngang của các điểm trắc địa được xác định tương ứng với mảng Thái Bình Dương được chọn làm mảng quy chiếu.

\begin{tabular}{|c|c|c|c|c|}
\hline Mảng kiến tạo & $\begin{array}{c}\mathrm{B}_{X} \\
\text { mas/a }\end{array}$ & $\begin{array}{l}\Omega_{Y} \\
\text { mas/a }\end{array}$ & $\begin{array}{l}3 y \\
\text { mas/a }\end{array}$ & $\begin{array}{r}\Omega \\
0 / \mathrm{Ma}\end{array}$ \\
\hline Thái Bình Dương & $-0,411 \pm 0,007$ & $1,036 \pm 0,007$ & $-2,166 \pm 0,009$ & $0,677 \pm 0,002$ \\
\hline Amurian & $-0,190 \pm 0,040$ & $-0,442 \pm 0,051$ & $0,915 \pm 0,049$ & $0,287 \pm 0,008$ \\
\hline Nazca & $-0,330 \pm 0,011$ & $-1,551 \pm 0,029$ & $1,625 \pm 0,013$ & $0,631 \pm 0,005$ \\
\hline Caribean & $0,049 \pm 0,201$ & $-1,088 \pm 0,417$ & $0,664 \pm 0,146$ & $0,354 \pm 0,122$ \\
\hline Nam Mỹ & $-0,243 \pm 0,009$ & $-0,311 \pm 0,010$ & $-0,154 \pm 0,009$ & $0,118 \pm 0,002$ \\
\hline Nam Cực & $-0,252 \pm 0,008$ & $-0,302 \pm 0,006$ & $0,643 \pm 0,009$ & $0,209 \pm 0,003$ \\
\hline Ấn Độ & $1,232 \pm 0,031$ & $0,303 \pm 0,128$ & $1,540 \pm 0,030$ & $0,554 \pm 0,017$ \\
\hline Australia & $1,504 \pm 0,007$ & $1,172 \pm 0,007$ & $1,228 \pm 0,007$ & $0,630 \pm 0,002$ \\
\hline Nubia & $0,095 \pm 0,009$ & $-0,598 \pm 0,007$ & $0,723 \pm 0,009$ & $0,262 \pm 0,003$ \\
\hline Somalia & $-0,080 \pm 0,028$ & $-0,745 \pm 0,030$ & $0,897 \pm 0,012$ & $0,325 \pm 0,007$ \\
\hline Arabia & $1,202 \pm 0,082$ & $-0,054 \pm 0,100$ & $1,485 \pm 0,063$ & $0,531 \pm 0,027$ \\
\hline Á - Âu & $-0,083 \pm 0,008$ & $-0,534 \pm 0,007$ & $0,750 \pm 0,008$ & $0,257 \pm 0,002$ \\
\hline Bắc Mỹ & $0,035 \pm 0,008$ & $-0,662 \pm 0,009$ & $-0,100 \pm 0,008$ & $0,186 \pm 0,002$ \\
\hline Sundaland & $0,047 \pm 0,381$ & $-1,000 \pm 1,570$ & $0,975 \pm 0,045$ & $0,388 \pm 0,308$ \\
\hline
\end{tabular}

Bảng 1 
Việc nghiên cứu chuyển dịch của các mảng kiến tạo được xây dựng dựa trên các dữ liệu trắc địa, địa chất, địa vật lý và điều kiện (5). Các dữ liệu trắc địa bao gồm các kết quả đo lặp trên các trạm VLBI, SLR, IGS và các điểm trắc địa thuộc các dự án ở các khu vực khác nhau trên thế giới. Trong tài liệu (Drewes, $H$. (2008)) đã công bố mô hình trường vận tốc chuyển dịch ngang VEMOS2008 của khu vực Nam Mỹ được xác định từ các dự án địa động lực như dự án SIRGAS (1995 -2000) và các dự án được thực hiện trong những năm đầu của thế kỷ XXI như CAP, CASA, CAGA, SNAPP. Trong tài liệu (Mora - Páez, H. (2012)) đã trình bày các kết quả nghiên cứu chuyển động mảng Caribbe và các vùng phụ cận phục vụ công tác dự báo động đất ở vùng Caribbe, Trung Mỹ và Bắc Andes dựa trên mạng lưới GEORED với 60 trạm CORS và mạng lưới COCONet với 6 trạm CORS ở Colombia.

Theo tài liệu (Tretyak, K., V. Romaniuk (2013)), dự án địa động lực khu vực Trung Âu (CERGOP) đã được triển khai từ năm 1993 với 14 nước tham gia bao gồm Albania, Austria, Bosnia - Herzegovina, Bulgaria, Croatia, Cộng hòa Czech, CHLB Đức, Hungary, Italy, Romania, Ba Lan, Slovakia, Slovenia và Ukraine.

Trong tài liệu (Michel, G.W., M. Becker (2000)) đã thông báo kết quả quan trắc dịch động kiến tạo trên mạng lưới GEODYSSEA gồm 42 điểm GPS bao phủ lục địa Á-Âu, biển Philippine, Ân Độ, mảng Australia, vùng lõm Sumatra, Iran và đứt gãy Philippine. Trong tài liệu (Pei Zhen Zang, Zhengkang Shen, Min Wang (2004)) đã thông báo kết quả đo dịch động trên cao nguyên Tibet từ kết quả đo mạng lưới GPS gồm 553 điểm. Trong tài liệu (Vernant, Ph., F. Nilforonshan, D. Hatzfeld (2004)) đã thông báo sử dụng kết quả đo trên mạng lưới GPS gồm 27 điểm nằm ở Iran và phía Bắc Oman để nghiên cứu chuyển dịch của vùng núi Himalaya-Alpine. Trong tài liệu (Socquet, A., Ch. Vigny, N. Chamot-Rooke. (2006)) đã thông báo kết quả nghiên cứu chuyển dịch của các mảng Ấn Độ và Sunda nhờ kết quả đo GPS.

Trong sự phối hợp với các nước khu vực Châu Á-Thái Bình Dương để nghiên cứu chuyển dịch vỏ Trái đất tại khu vực này trong khuôn khổ dự án PCGIAP đã có 41 nước tham gia, trong đó có Việt Nam. Dựa trên 190 trạm GPS được đo trong giai đoạn 1997 - 2008, trong tài liệu (Matsuzaka, S., P. Cheng, J. Manning (2009)) đã công bố trường chuyển dịch ngang của khu vực Châu Á - Thái Bình Dương.

Các điểm trắc địa tham gia việc nghiên cứu chuyển dịch các mảng kiến tạo được phân bố đều có thể được trên tất cả các mảng kiến tạo, không cần thiết được bố trí đều trên các các biên của các mảng. Các dữ liệu đo GNSS trên các điểm trắc địa được bố trí trên các mảng kiến tạo được xử lý trong ITRF bằng phần mềm khoa học, ví dụ Bernese.

\section{Kết luận}

Nghiên cứu chuyển dịch các mảng kiến tạo là đối tượng nghiên cứu của lĩnh vực Động học mảng (Plate Tectonics) trong việc phối hợp với các lĩnh vực Trắc địa cao cấp và Địa vật lý. Phạm vi nghiên cứu là khu vực rộng lớn bao trùm nhiều mảng kiến tạo lớn từ phạm vi khu vực đến toàn cầu với sự tham gia của nhiều nước có liên quan. Sản phẩm chính của nghiên cứu chuyển dịch các mảng kiến tạo là các bộ vận tốc quay Euler $\Omega_{X}, \Omega_{Y}, \Omega_{Z}$ của các mảng kiến tạo được xác định từ các vectơ chuyển dịch ngang của các điểm trắc địa được bố trí trên các mảng kiến tạo kết hợp với các dữ liệu địa chất và địa vật lý. 
Ngày nay, các bộ vận tốc quay Euler $\Omega_{X}, \Omega_{Y}, \Omega_{Z}$ của các mảng kiến tạo là nguồn dữ liệu quan trọng để hiệu chỉnh các tọa độ không gian của các điểm GNSS được xác định bằng công nghệ GNSS vào ITRF xác định khi tính đến sự chuyển dịch của các điểm này do hoạt động của các mảng kiến tạo.O

\section{Tài liệu tham khảo}

[1]. Altamimi, Z., Métivier, L., and Collilieux, X., 2012. ITRF2008 plate motion model. Journal of Geophysical research, Vo. 117, B07402, doi: 10.1029/2011JB008930.

[2]. Argus, D. F., Gordon, R. G., and DeMets, C., 2011. Geologically current motion of 56 plates relative to the no-net-rotation reference frame, Geochemistry, Geophysics, Geosystems, Vol. 12, No. 11, Q11001, doi: 10.1029/2011GC003751, ISN: 1525 - 2027.

[3]. Boucher, C. and Altamimi, Z.. Memo: Specifications for reference frame fixing in the analysis of a EUREF GPS campaign. http://lareg.esng.ign.fr/EUREF/

[4]. Condie K.C. (1997). Plate Tectonics and Crustal Evolution. Fourth edition, Institute of Mining and Technology, Cocorro, New Mexico, ISBN: 0750633867, 294 p, Bookcraft (Bath) Ltd.

[5]. DeMets, C., R.G. Gordon, D.F. Argus, and S. Stein (1994), Effect of recent revisions to the geomagnetic reversal time scale on estimates of curent plate motions. Geophysical Research Letters, Vol. 21, N0. 20, pp. 2191 - 2194.

[6]. DeMets, C., R. G., Gordon, and D. F., Argus (2010). Geologically current plate motions, Geophysical Journal International, Vol. 181, No. 1, pp. 1 - 80, doi: 10.1111/j.1365246X.2009.04491.X

[7]. Drewes, H. (2008). Update of the Velocity Field model of South America, SIRGAS General Assembly, Montevideo, Uruguay, 18p.

[8]. Matsuzaka, S., P. Cheng, J. Manning (2009). Report for $15^{\text {th }}$ PCGIAP Meeting at $18^{\text {th }}$ UNRCC - AP Working Group 1 Regional Geodesy. 26 october 2009, Bankok, Thailand.

[9]. McCarthy, D. D., 1996. “IERS Conventions, 1992”, IERS Tech. Note 21, Central Bureau of IERS - Observatoire de Paris 61, avenue de l'observatoire F-75014 Paris, France.

[10]. Michel, G.W., M. Becker (2000). Crustal motion in E- and SE-Asia from GPS measurements. Earth Plates Space, 52, 713-720,2000

[11]. Mora - Páez, H. (2012). GEORED project Spatial Geodesy Network for Geodynamics Research in Colombia, South America. San Jose des Canpos, Brasil, 42 p.

[12]. Moritz, H. and I.I. Mueller (1987). Earth Rotation: Theory and Observation. Ungar, New York.

[13]. Munk, W.H.\& MacDonald, G.J.F. (1960).The Rotation of the Earth: A Geophysical Discussion, Cambridge University Press, Cambridge, UK.

[14]. Pei Zhen Zang, Zhengkang Shen, Min Wang (2004). Continuous deformation of the 
Tibetan plateau from global positioning system data. Geology. September 2004, V.32, No 9, p.809-812

[15]. Petit G., Luzum B. (2010). IERS Conventions (2010). IERS Technical Note No 36, Verlag dés Bundesamts fur Kartographie und Geodasie. Frankfurt am Main 2010, 179 pp.

[16]. Plate tectonics. From Wikipedia, the free encyclopedia

https://en.wikipedia.org/wiki/Plate_tectonics

[17]. Riguzzi F. (2008). From the Global Scale to the Miditerranean Plate Kinematics. A dissertation for the degree of Doctor of Philosophy Field in Geodynamics and Geophysics. Department of Earth Sciences, La Sapieuza University of Roma, Italy.

[18]. Socquet, A., Ch. Vigny, N. Chamot-Rooke. (2006). India and Sunda plates motion and deformation along their boundary in Myanmar determined by GPS. Journal of Geophysical Research, Vol.111, 2006.

[19]. tefka V. (2010). Angular velocity of tectonic plates determined by non - rigorous combination of space geodetic techniques. Acta Geodyn. Geomater., Vol. 7, No. 3 (159): $275-280$.

[20]. Tretyak, K., V. Romaniuk (2013). Using GNSS Technologies for Research Features Vertical Movements of the Crust of Europe. Geomatics and Enviromental Engineering, Vol. 7, No. 2, pp. $71-77$.

[21]. Vernant, Ph., F. Nilforonshan, D. Hatzfeld (2004). Present-day crustal deformation and plate kinematics in the mildle East constrained by GPS measurements in Iran and northern Oman. Geophys. J. Int. (2004) 157,381-398

[22]. Жаров В.Е. (2002). Сфрерическая астрономия. Москва, МГУ, Астронет http://www.astronet.ru/db/msg/1190817/node25.html

Zarov V.E. (2002). Thiên văn cầu. Moskva, Astronet, MGU, http://www.astronet.ru/db/msg/1190817/node25.html. O

\section{Summary}

\section{Specific characters of research of crustal movement of tectonic plates}

Ha Minh Hoa, Vietnam Institute of Geodesy and Cartography

This article analyses scientific and practic bases of research of crustal movement of the tectonic plates. Research results of this article will allow distinguish research of the crustal movement of tectonic plates from research of activity of the faults to develop geodynamic research in Vietnam. $O$ 